3. Lamari L., Bernier C.C. Toxin of Pyrenophora tritici-repentis: host specificity, significance in desease and inheritance of host-reaction // Phytopathology, 1989, 79, p.740-744.

4. Кохметова А.М., Кремнева О.Ю., Кейшилов Ж.С., Султанова Н. Ж. Расовый состав и вирулентность изолятов Pyrenophora tritici-repentis в Северо-кавказском регионе России и Республике Казахстан // Eurasian Journal of Applied Biotechnology. 2016. №3. С.57-66.

DOI 10.18699/GPB2020-45

\title{
Рост и развитие гибридов астильбы в лесостепи Алтайского края
}

Куранда Ю.В., м.н.с.

ФГБНУ Федеральный Алтайский научный цуентр агробиотехнологий, г. Барнаул, Россия.

*e-mail: margo.22@mail.ru

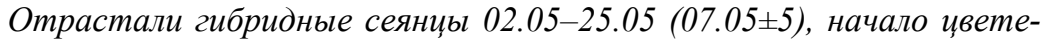

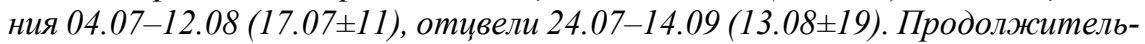
ность ияветения была 12-45 (27士10 дней). Высота гибридов составила 20,0-

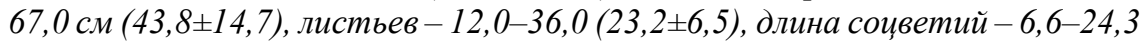

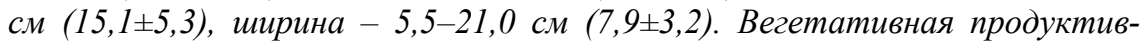
ность популяции сеянцев составила 4-35 (16士8) розеток листьев, генеративная - 1-29 (8土7) ияветоносов.

Ключевье слова: астильба, гибриды, фенология, морфология, продуктивность.

\section{Growth and development of Astilba hybrids in the forest-steppe of the Altai territory}

Kuranda, Yu., Junior researcher, Federal state scientific institution of FANZA, Department NIISS Barnaul, Russia.margo.22@mail.ru

Hybrid seedlings grew on 02.05-25.05 (07.05 \pm 5$)$, the beginning of flowering on 07.07-12.08 (17.07 \pm 11$)$ faded on 07.24-14.09 (13.08 \pm 19$)$. The duration of flowering was 12-45 (27 \pm 10 days). The height of the hybrids was 20.0-

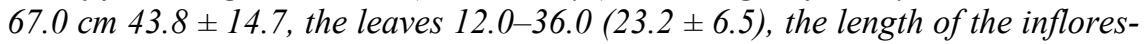
cences was 6.6-24.3 cm (15.1 \pm 5.3$)$, width $-5.5-21.0 \mathrm{~cm}$ (7.9 \pm 3.2$)$. The vegetative productivity of the seedling population was 4-35 (16 \pm 8$)$ rosettes of leaves, generative - 1-29 (8 \pm 7) peduncles.

Key words: astilba, hybrids, phenology, morphology, productivity.

Астильба (Astilbe Buch-Наm.) - род многолетних травянистых растений, популярных в ландшафтной архитектуре. Введена в культуру во II по- 
ловине XIX века [1]. Первым селекционером был Э. Лемуан (1823-1911), затем Г. Арендс и другие, в настоящее время селекция ведется на Украине и Голландии, создано 200-250 сортов [2]. На Алтае интродукцию начали И.В. Верещагина и 3.В. Долганова; здесь важно создание местного ассортимента растений [3]. Хорошая всхожесть семян и разнообразное по фенологии и морфологии потомство открывает большие возможности для селекции культуры [5].

Цель исследований - оценить возможности роста и развития гибридных сеянцев астильбы в условиях лесостепной зоны Алтая.

Исследования проведены в 2019 г., объектами исследования служили 26 сеянцев от свободного опыления, высаженные в коллекционный питомник в 2017 г. Сбор семян - X.2013 г., посев IV.2014 г., наблюдения - по Методике ГСИ [4], анализ погодных условий по данным метеостанции НИИСС.

Результаты. Вегетационный период 2019 г. был наиболее теплый, слабо увлажненный, ГТК - 0,9. Первая декада апреля была теплее нормы на $3,7^{\circ} \mathrm{C}$, во II и III декадах температура была в пределах многолетнего значения, снежный покров сошел 17 апреля. Массовое отрастание сеянцев наблюдалось в I декаде мая 05.05 \pm 5 (02.05-25.05), единичные сеянцы - только в II-III декаде (табл. 1). Весенние заморозки 2-5.05 $\left(-5{ }^{\circ} \mathrm{C}\right), 16.05\left(-4{ }^{\circ} \mathrm{C}\right)$ и $27.05\left(-2,2{ }^{\circ} \mathrm{C}\right)$ вызвали гибель надземной части, включая отрастающие цветоносы. Поэтому рано зацветающие материнские растения сортов Deutchland, Ellie, а также Brautschleier в 2019 г. образовали только единичные, не достигающие нормальных размеров соцветия, как и черенки сорта Superba.

Таблица 1 - Фенологическое развитие гибридов астильбы

\begin{tabular}{|c|c|c|c|c|}
\hline \multirow{2}{*}{$\begin{array}{c}\text { Материнский сорт, } \\
\text { гибрид }\end{array}$} & \multirow{2}{*}{$\begin{array}{c}\text { Дата отрас- } \\
\text { тания } \\
\end{array}$} & \multicolumn{3}{|c|}{ Цветение, дата } \\
\hline & & начало & окончание & период, дни \\
\hline 1 & 2 & 3 & 4 & 5 \\
\hline Brautschleier & $27.04 \pm 6$ & $05.07 \pm 6$ & $30.07 \pm 9$ & $23 \pm 3$ \\
\hline $01-14-03$ & 10.05 & 08.07 & 26.07 & 18 \\
\hline 01-14-09 & 06.05 & 21.07 & 08.08 & 18 \\
\hline 01-14-10 & 10.05 & 15.07 & 08.08 & 24 \\
\hline 01-14-11 & 25.05 & 15.07 & 08.08 & 24 \\
\hline Deutchland & $29.04 \pm 6$ & $27.06 \pm 6$ & $17.07 \pm 7$ & $20 \pm 1$ \\
\hline $02-14-01$ & 03.05 & 04.07 & 24.07 & 20 \\
\hline $02-14-02$ & 02.05 & 06.07 & 26.07 & 20 \\
\hline $02-14-03$ & 02.05 & 05.07 & 26.07 & 21 \\
\hline 02-14-04 & 03.05 & 05.07 & 26.07 & 21 \\
\hline $02-14-06$ & 06.05 & 08.07 & 28.07 & 20 \\
\hline 02-14-08 & 12.05 & 08.07 & 24.07 & 16 \\
\hline 02-14-09 & 05.05 & 05.07 & 24.07 & 19 \\
\hline $02-14-12$ & 06.05 & 06.07 & 26.07 & 20 \\
\hline
\end{tabular}




\begin{tabular}{|l|c|c|c|c|}
\hline \multicolumn{1}{|c|}{$\mathbf{2}$} & $\mathbf{3}$ & $\mathbf{4}$ & $\mathbf{5}$ \\
\hline $02-14-13$ & 07.05 & 07.07 & 28.07 & 21 \\
\hline Ellie & $28.04 \pm 8$ & $05.07 \pm 7$ & $28.07 \pm 6$ & $23 \pm 3$ \\
\hline \multirow{2}{*}{$04-14-02$} & 06.05 & 26.07 & 07.08 & 12 \\
\cline { 3 - 5 } & & 12.08 & 10.09 & 29 \\
\hline Superba & $27.04 \pm 7$ & $18.07 \pm 4$ & $23.08 \pm 8$ & $35 \pm 4$ \\
\hline $05-14-01$ & 03.05 & 26.07 & 26.08 & 31 \\
\hline $05-14-02$ & 03.05 & 02.08 & 09.09 & 38 \\
\hline $05-14-03$ & 13.05 & 07.08 & 14.09 & 38 \\
\hline $05-14-04$ & 03.05 & 26.07 & 09.09 & 45 \\
\hline $05-14-05$ & 02.05 & 26.07 & 09.09 & 45 \\
\hline $05-14-06$ & 02.05 & 26.07 & 09.09 & 45 \\
\hline $05-14-07$ & 03.05 & 26.07 & 09.09 & 45 \\
\hline Bronzelaub & $27.04 \pm 9$ & 29.06 & 24.07 & 25 \\
\hline $06-14-01$ & 02.05 & 24.07 & 26.08 & 33 \\
\hline $06-14-02$ & 02.05 & 15.07 & 10.08 & 26 \\
\hline $06-14-05$ & 03.05 & 15.07 & 05.08 & 21 \\
\hline $06-14-06$ & 03.05 & 20.07 & 12.08 & 23 \\
\hline $06-14-08$ & 05.05 & 24.07 & 18.08 & 25 \\
\hline min-max & $\mathbf{0 2 . 0 5 - 2 5 . 0 5}$ & $\mathbf{0 4 . 0 7 - 1 2 . 0 8}$ & $\mathbf{2 4 . 0 7 - 1 4 . 0 9}$ & $\mathbf{1 2 - 4 5}$ \\
\hline сpeднеe $\pm \boldsymbol{\sigma}$ & $\mathbf{0 5 . 0 5} \pm \mathbf{5}$ & $\mathbf{1 7 . 0 7} \pm \mathbf{1 1}$ & $\mathbf{1 3 . 0 8} \pm \mathbf{1 9}$ & $\mathbf{2 7} \pm \mathbf{1 0}$ \\
\hline
\end{tabular}

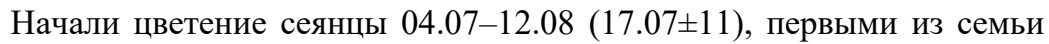
Deutchland (04.07-08.07) близко к материнскому сорту (05.07), который в 2013-2015 гг. зацветал на 8 дней раньше. Вторыми зацвели гибриды Brautschleier (08.07-15.07) близко к родительской форме - 12.07 (01-14-09 на 9 дней позже), которая в 2013-2015 гг. цвела на 7 дней раньше. Затем начал цветение гибрид Ellie (26.07) - через 6 дней после материнского сорта (20.07 в 2019 г.) и спустя 5 дней после окончания цветения первых соцветий (07.08), зацвел вторично (12.08) на 23 дня позже материнского растения (цветение проходило в два этапа - см. табл. 1). Цветение сеянцев Bronzelaub началось 15.07-24.07, на 7-16 дней после материнского сорта (08.07), Superba - 26.07 близко к родительской форме (гибриды 05-14-02 и 05-14-03, соответственно 02.08 и 07.08$)$.

Окончание цветения отмечалось 24.07-14.09 (13.08 \pm 19$)$. Первыми отцвели гибриды Deutchland (24.07-28.07) и Brautschleier (26.07-08.08) вместе с материнскими сортами (24.07 и 05.08 соответственно). Затем Bronzelaub 05.08-26.08, гибрид 06-14-05 в одно время с родительской формой (05.08), остальные - на 5-19 дней позже. Сеянцы сорта Superba заканчивали цветение в I-II декаде сентября, 05-14-01 в августе (26.08). Длительность цветения $12-45$ дней $(27 \pm 10)$, наименьшая - у сеянцев Brautschleier 18-24 и Deutchland 16-21 день. В среднем по годам сорт Bronzelaub цвел около 25 дней, в 2019 
г. - 28, гибрид 06-14-01 дольше его на 5 дней, остальные на 2-7 дней меньше. Длительно цвели сеянцы Superba (31-45 дней) и имели очень приятный аромат. Во влажном 2013 г. сорт Superba цвел 39 дней, засушливом 2015 г. - 31 день.

Высота сеянцев 20-67 см $(43,8 \pm 14,7)$, листьев 12-36 см $(23,2 \pm 6,5)$ : сорта Brautschleier - 40-52 см, Deutchland - 20-49 см, что на 9-21 см и 3422 см соответственно ниже материнских сортов (гибрид 02-14-12 - на уровне). Сеянцы Ellie и Superba достигли высоты материнского растения (табл. 2), или ниже его на 9-13 см (05-14-03 - на 44). Сорт Bronzelaub в 2019 г. достиг 70 см, гибриды ниже его на 10-28 см.

Таблища 2 - Морфологическое развитие гибридов астильбы

\begin{tabular}{|l|c|c|c|c|c|c|}
\hline \multirow{2}{*}{$\begin{array}{c}\text { Материнский } \\
\text { сорт, гибрид }\end{array}$} & \multicolumn{2}{|c|}{ Высота, см } & \multicolumn{2}{c|}{ Соцветие, см } & \multicolumn{2}{c|}{ Число, шт.* } \\
\cline { 2 - 7 } \multicolumn{1}{c|}{ растений } & листьев & длина & ширина & розеток & $\begin{array}{c}\text { соцве- } \\
\text { тий }\end{array}$ \\
\hline Brautschleier & $\mathbf{2}$ & $\mathbf{3}$ & $\mathbf{4}$ & $\mathbf{5}$ & $\mathbf{6}$ & 7 \\
\hline $01-14-03$ & 40 & $27,9 \pm 6,9$ & $32,3 \pm 12$ & $20,4 \pm 6,8$ & 22 & 20 \\
\hline $01-14-09$ & - & 12 & - & - & 14 & 9 \\
\hline $01-14-10$ & 50 & 20 & 23,0 & 10,0 & 6 & 1 \\
\hline $01-14-11$ & 52 & 27 & 20,0 & 21,0 & 30 & 23 \\
\hline Deutchland & $54,4 \pm 4,2$ & $38,1 \pm 1,0$ & $21,6 \pm 5,5$ & $8,8 \pm 1,1$ & 31 & 22 \\
\hline $02-14-01$ & 32 & 19 & 7,8 & 9,6 & 22 & 10 \\
\hline $02-14-02$ & 27 & 21 & 10,5 & 5,5 & 14 & 2 \\
\hline $02-14-03$ & 32 & 18 & 11,3 & 11,3 & 16 & 4 \\
\hline $02-14-04$ & 25 & 19 & 8,9 & 6,6 & 15 & 2 \\
\hline $02-14-06$ & 20 & 14 & 6,6 & 5,6 & 17 & 3 \\
\hline $02-14-08$ & 27 & 20 & 8,0 & 8,0 & 25 & 1 \\
\hline $02-14-09$ & 26 & 22 & 11,0 & 8,7 & 16 & 4 \\
\hline $02-14-12$ & 49 & 23 & 14,0 & 8,5 & 26 & 4 \\
\hline $02-14-13$ & 22 & 13 & 8,5 & 7,5 & 9 & 2 \\
\hline Ellie & $37,0 \pm 6,1$ & $15,7 \pm 4,7$ & $17,0 \pm 3,3$ & $9,2 \pm 5,1$ & 7 & 5 \\
\hline $04-14-02$ & 36 & 16 & 12,3 & 7,6 & 9 & 3 \\
\hline Superba & $78,7 \pm 13,0$ & $33,9 \pm 8,3$ & $35,6 \pm 9,2$ & $9,0 \pm 1,0$ & 12 & 9 \\
\hline $05-14-01$ & 52 & 36 & 14,6 & 6,0 & 8 & 4 \\
\hline $05-14-02$ & 56 & 33 & 19,6 & 5,8 & 15 & 7 \\
\hline $05-14-03$ & 34 & 17 & 18,5 & 6,0 & 4 & 2 \\
\hline $05-14-04$ & 64 & 25 & 22,2 & 6,2 & 10 & 9 \\
\hline $05-14-05$ & 67 & 30 & 24,3 & 6,6 & 7 & 3 \\
\hline $05-14-06$ & 55 & 25 & 18,5 & 6,0 & 9 & 3 \\
\hline $05-14-07$ & 65 & 30 & 19,8 & 6,0 & 10 & 9 \\
\hline Bronzelaub & 77,7 & $35,8 \pm 13,4$ & 26,8 & 12,6 & 13 & 14 \\
\hline & & & & & & \\
\hline
\end{tabular}




\begin{tabular}{|c|c|c|c|c|c|c|}
\hline $\mathbf{1}$ & $\mathbf{2}$ & $\mathbf{3}$ & $\mathbf{4}$ & $\mathbf{5}$ & $\mathbf{6}$ & $\mathbf{7}$ \\
\hline $06-14-01$ & 52 & 30 & 12,4 & 7,0 & 35 & 29 \\
\hline $06-14-02$ & 49 & 24 & 16,4 & 6,6 & 19 & 7 \\
\hline $06-14-05$ & 60 & 30 & 20,6 & 9,4 & 18 & 14 \\
\hline $06-14-06$ & 42 & 23 & 14,6 & 8,2 & 21 & 19 \\
\hline $06-14-08$ & 60 & 33 & 18,4 & 6,6 & 19 & 14 \\
\hline min-max & $20-67$ & $12-36$ & $6,6-24,3$ & $5,5-21,0$ & $4-35$ & $1-29$ \\
\hline среднее $\pm \boldsymbol{\sigma}$ & $43,8 \pm 14,7$ & $23,2 \pm 6,5$ & $15,1 \pm 5,3$ & $7,9 \pm 3,2$ & $16 \pm 8$ & $8 \pm 7$ \\
\hline
\end{tabular}

* примечание: максимальное значение у материнских сортов за 2013-2015 гг.

Длина соцветий не достигала размеров материнского сорта и составила от 6,6 до 24,3 см $(15,1 \pm 5,3)$, ширина от 5,5 до 21,0 см $(7,9 \pm 3,2)$. Продук-

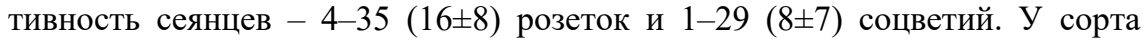
Bronzelaub она высокая - 8-35 розеток и 7-29 соцветий. Гибрид 06-14-01 наиболее продуктивный (35 и 29 соответственно). Сеянец Brautschleier 0114-11 имеет 30 розеток и 23 соцветия (второй по продуктивности), у остальных на 8-16 розеток меньше, чем у материнского сорта (данные по сеянцам не полные вследствии усыхания надземной части). В семье Deutchland гибриды 02-14-01, 02-14-08 и 02-14-12 имеют свыше 25 розеток, 02-14-03 - менее 9, остальные 14-17. Количество соцветий 1-4, (что связано с обмерзанием надземной части), максимум (10) - у гибрида 02-14-01. Сеянец Ellie хорошо разрастается, гибриды Superba 05-14-02, 05-14-04 и 05-14-07 имеют 10-15 розеток и 7-9 цветоносов - они лидеры по продуктивности в семье, остальные - 4-9 розеток листьев и 2-4 соцветия, что на 3-8 и 5-7 соответственно меньше, чем у материнского сорта.

По итогам изучения роста и развития можно сделать выводы:

1. Зацветают сеянцы 04.07-12.08, в ранние сроки Deutchland, Brautschleier - близко к материнскому сорту, Bronzelaub - на 7-16 дней позже, Ellie - на 6, поздние - Superba - с материнским сортом, а два сеянца на 15-20 дней позднее.

2. Цветение продолжается 12-45 дней: кратковременное Brautschleier и Deutchland, среднее - у гибридов Bronzelaub (один дольше родительской формы), длительное - Superba.

3. Высота гибридов варьировала от 20 до 67 см, длина соцветий от 6,6 до 24,3, ширина - от 5,5 до 21,0 см, что меньше растений материнских сортов. Вегетативная продуктивность 4-35 розеток, генеративная - 1-29 соцветий. Сеянцы Bronzelaub лидируют по вегетативной и генеративной продуктивности, Deutchland - только по вегетативной. Продуктивность сеянцев Superba и Brautschleier на уровне, либо ниже родительской формы (01-14-11 выше).

\section{Список литературь}

1. Иевиня С.О., Лусиня М.А. Астильбы. Интродукция в Латвийской ССР. - Рига: 
Зинанте, 1975. - $120 \mathrm{c.}$

2. Кабанов А.В. Проблемы охранения генофонда декоративных растений на примере коллекции рода Astilbe Buch-Ham в отделе декоративных растений ГБС РАН. // Цветоводство: традиции и современность: матер. VI Межд. науч. конф. / Отв. ред. А.С. Демидов. - Белгород: ИД «Белгород» НИУ «БелГУ», 2013 г. - С. 271-274.

3. Верещагина И.В. Культура цветочных растений в Алтайском крае. - Барнаул: Алтайское книж. изд-во, 1968. - 143 с.

4. Методика государственного сортоиспытания сельскохозяйственных культур: декоративные культуры. М.: Изд-во Мин-ва сел. хоз-ва РСФСР, 1968. Вып. 6. - С. $56-89$.

5. Куранда Ю.В. Возможность семенного размножения и первичная оценка сеянцев Astilbe Buch-Ham. от свободного опыления сортов. // Проблемы промышленной ботаники индустриально развитых регионов. / Отв. ред. Куприянов А.Н. Кемерово: ФИЦ УУХ СО РАН, 2018 г. - С. 72-74.

DOI 10.18699/GPB2020-46

\section{Генетическое разнообразие и биохимическая ценность культур Raphanus L. коллекции ВИР}

Курина А.Б. м.н.с., Соловьева А.Е. к.б.н., с.н.с., Артемьева А.М. к.с.-х.н., в.н.с. ФГБНУ «Федеральный исследовательский центр Всероссийский институт генетических ресурсов растений им. Н.И. Вавилова (ВИР)», г. Санкт-Петербург, Россия.

e-mail: nastya_n11@mail.ru

Изучение генофонда культур Raphanus L. имеет большое значение в вопросах оценки исходного материала и выявления источников хозяйственно-ценных признаков для селекции. Это связано с недостаточной изученностью физиологической реакции образцов различных сортотипов на условия выращиввания, биохимических особенностей, пределов изменчивости признаков селекционного интереса, экологической пластичности, адаптационных возможностей, устойчивости к абиотическим и биотическим стрессам. Изучение разнообразия культур Raphanus L. коллекции ВИР позволит всесторонне оценить коллекцию, описать новые формы и сортотипь, выявить биологические закономерности формирования фотосинтетического аппарата, урожая, устойчивости к биотическим и абиотическим стрессорам. В результате исследований оценен в контрастных условиях выращивания диапазон проявления признаков интереса, их стабильность/лабильность, определень эколого-географические группь и сортотипь, которые содержат источники ценных признаков, выделены образцы с высоким адаптационным потенциалом. 